\title{
Evaluation of a non-contact method for measuring vibration of rolling bearings in industrial conditions
}

\author{
Ocena bezdotykowej metody pomiaru drgań łożysk tocznych \\ w warunkach przemysłowych
}

\section{STANISŁAW ADAMCZAK MATEUSZ WRZOCHAL NUMAN DURAKBASA *}

\begin{abstract}
Using of laser vibrometers in vibration measurement systems brings additional benefits due to the lack of impact of the sensor on the tested measuring system. Recently, leading rolling bearing manufacturers are equipping their diagnostic measuring systems with non-contact sensors. Doppler laser vibrometers are used interchangeably for electrodynamic sensors. This paper attempts to assess the vibrometer in use for measuring vibration of rolling bearings in industrial conditions.
\end{abstract}

KEYWORDS: rolling bearings, measurements, vibrations, vibrometer

\section{Introduction}

Each rolling bearing manufacturer has a system that should meet requirements of rolling bearing vibration measurement standards. Very different technical solutions of individual measuring system assemblies are used. In addition, systems are being used where the laser vibrometer can be used interchangeably instead of the electrodynamic sensor [1]. Electrodynamic sensor and Doppler vibrometer despite the fact that their operation is based on different physical principles, they are used to measure the same size - vibration velocity.

In the $80 \mathrm{~s}$ of the $20^{\text {th }}$ century, the first laser vibrometers were created, and since then they have quickly found new applications. A very comprehensive overview of the basic use of vibrometers is in [2]. Laser vibrometry is also used to measurements related to rolling bearings but, rarely, topics related to typical production issues. In [3] there is a description of the bearing ball surface measurements, and detecting cracks on their surface. Thanks to the direct measurement of the displacement velocity we get much more effective detection of defects in high frequency bands. The authors of [4] also deal with the subject of measuring profiles of manufactured bearing balls. The diagnostics of bearings already operating in devices are often described, too. The authors of $[5,6]$ present the monitoring of mounted bearings with a vibrometer in electric motors.

Available literature includes publications on comparative testing of the vibrometer with standard sensors. Research presented in [7] relate to the combination of a Doppler laser vibrometer with displacement and velocity sensors when measuring deflection and
DOI: https://doi.org/10.17814/mechanik.2020.2.5

bridge vibration. At work [8] comparative tests are carried out for smaller objects (measurement of electric motors vibration). The laser vibrometer and acceleration sensors are compared with each other. The research aimed at comparing contact and contactless sensors with reference to rolling bearings is carried out by the author in [9]. He tests a damaged bearing operating in a mechanical system and compares the results obtained from the vibrometer and vibration acceleration sensor (proper rolling bearing diagnostics). There are currently no published results comparing the results of rolling bearing vibration measurements measured with an electrodynamic sensor and a laser vibrometer in relation to the quality control of newly manufactured rolling bearings.

The advantage of no interference in the measuring system means that Doppler laser vibrometers could be used in conjunction with other contact sensors, and also very helpful for tests determining the metrological properties of rolling bearing vibration measurement systems. Therefore, research on the problems associated with the impact of the laser beam on the external surfaces of the tested bearings is necessary, as well as determining the scope of use of laser vibrometers in the study of bearing vibration measurement systems. So far, a preliminary analysis of comparing the effective value of signals for one type of bearing has been conducted [10]. This article presents a comparison of the effective value and the basic harmonics of the vibration signal spectrum of five rolling bearing groups.

\section{Methodology}

The research involved comparing the PSV-500 laser vibrometer with the electrodynamic vibration speed sensor SG4.3 operating in a standard bearing vibration measurement system (fig. 1). The measurements were carried out on a group of 50 bearings type 6204, five different manufacturers marked with letters $F$, $N, T, R$ and $S$. Each manufacturer was represented by 10 bearings. The tested rolling bearings had nitrile seals, individually marked by each manufacturer. The shaft on which the bearing was mounted rotated at a speed of $1800 \mathrm{rpm}$. The three-point pusher oush of the outer ring in the axial direction (visible in fig. 1) worked with a force of $60 \mathrm{~N}$.

\footnotetext{
* Prof. dr hab. inż. Stanisław Adamczak dr h.c. multi, adamczak@tu.kielce.pl, https://orcid.org/0000-0002-7797-6330 - Kielce University of Technology, Kielce, Poland

Mgr inż. Mateusz Wrzochal, mwrzochal@tu.kielce.pl - Kielce University of Technology, Kielce, Poland

Prof. dr hab. inż. Numan Durakbasa, numandurakbasa@tuwien.ac.at - Technische Universität Wien, Wien, Austria
} 


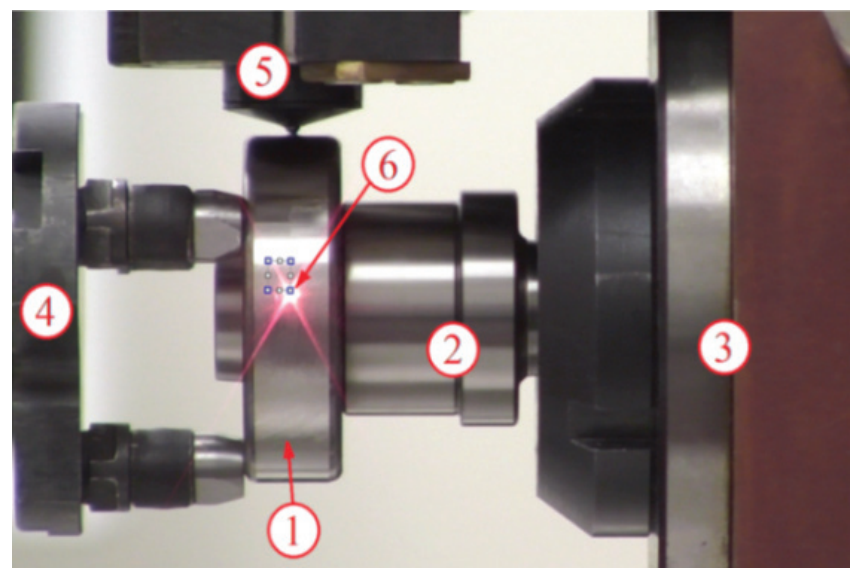

Fig. 1. STPPD measurement head [10]: 1 - tested bearing, 2 - shaft, 3 - spindle, 4 - three-point pusher, 5 - electrodynamic sensor SG 4.3, 6 - point measuring point of the PSV-500 vibrometer

Both devices measured radial vibrations in two perpendicular directions. Bearing was mounted on the shaft and the vibration was measured three times. Then the same bearing was mounted on the shaft in the reverse side and three measurements were also made. Between measurements, the bearings outer ring was turned a third of a turn. Signals from both devices were recorded in parallel for the same period of 6 seconds. This methodology allowed for obtaining 60 pairs of results for each of the five series. The sampling frequency of both systems was the same. Due to the fact that the devices collected data from two directions perpendicular to each other, the average values of parameters were calculated from three measurements on one side.

One of the problems with vibrometer measurements was the appearance of noise that caused spectrum distortion (fig. $2 b$ ). These data were not taken for analysis and accounted for $8 \%$ of all vibrometer measurements. Most rejected measurements had interference

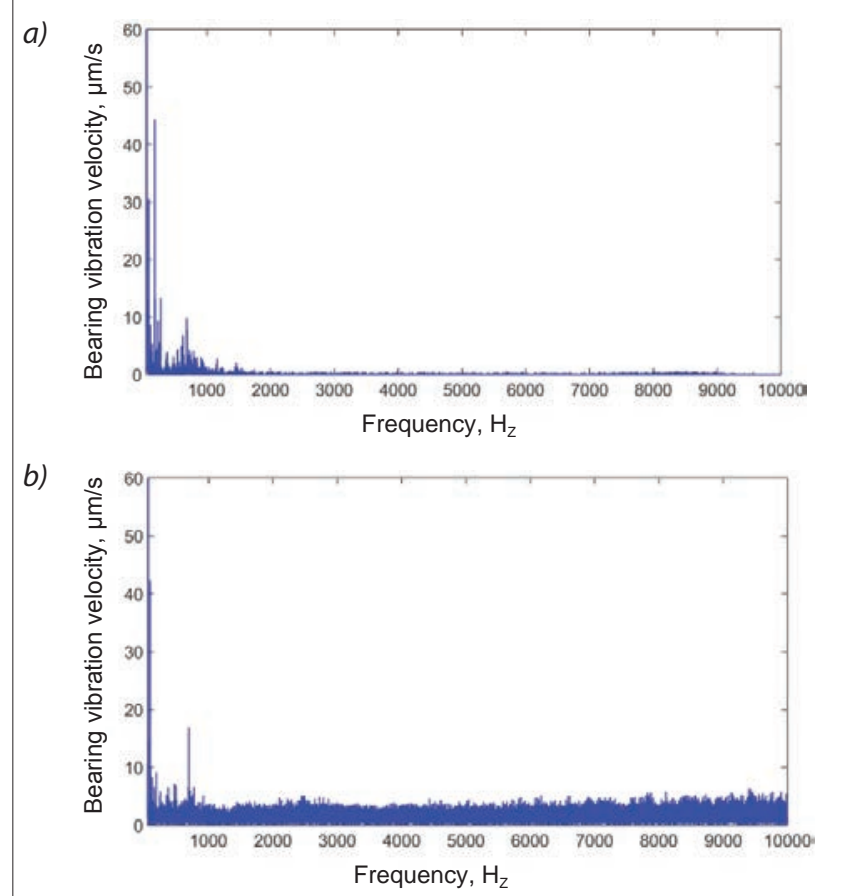

Fig. 2. Vibration velocity spectrum of a rolling bearing type 6204 obtained from the measurement with the PSV-500 laser vibrometer: a) signal without noise, $b$ ) signal containing noise in the whole frequency range in the high frequency band. Disturbances were less frequent in the medium band, but the least frequent in the low band. Measurements containing noise were not associated with specific bearings, they appeared accidentally in single measurements. Further research should examine the exact cause and eliminate the disturbed measurement signals obtained with the use of a vibrometer.

\section{Comparison of vibration signal basic harmonics}

The use of fast Fourier transform allows you to find the frequencies and amplitudes of individual vibration components of the time signal. Appearing harmonics are related to the geometrical and construction parameters of the rolling bearing and may indicate imperfections and damage to individual components. Knowing some bearing dimensions, we can calculate characteristic failure frequencies using standard formulas [11]. Analysis of the spectrum of vibration velocities obtained from parallel measurement with two devices, allows to distinguish individual components. Fig. 3 contains vibration spectra obtained from single measurements with an electrodynamic sensor $(a)$ and a vibrometer $(b)$.

Peaks with clearly high amplitude appear only up to a frequency of about $700 \mathrm{~Hz}$ (a wide range of the spectrum can be seen in fig. 2). The components shown on fig. 3 can be equated with typical frequencies calculated for the geometric dimensions of the 6204 bearing. Six harmonics with the highest amplitudes were selected for comparative analysis. The first of them (the highest for most measurements) corresponds to $60 \mathrm{~Hz}$. This frequency coincides with the second harmonic of the rotational frequency, as well as with the ball rotation frequency. For both electrodynamic

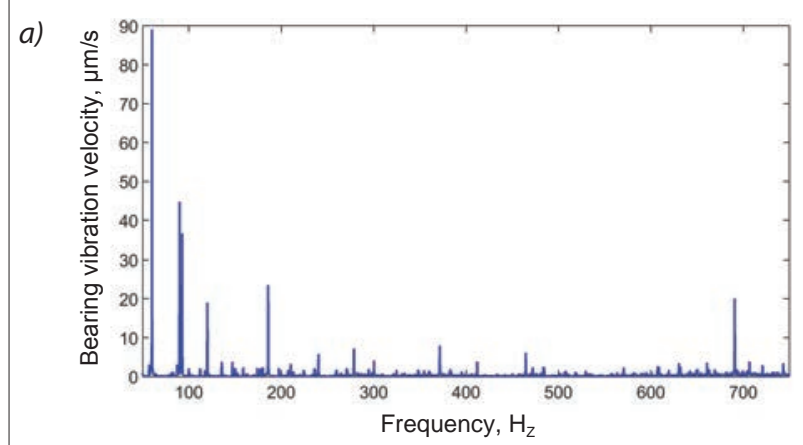

b)

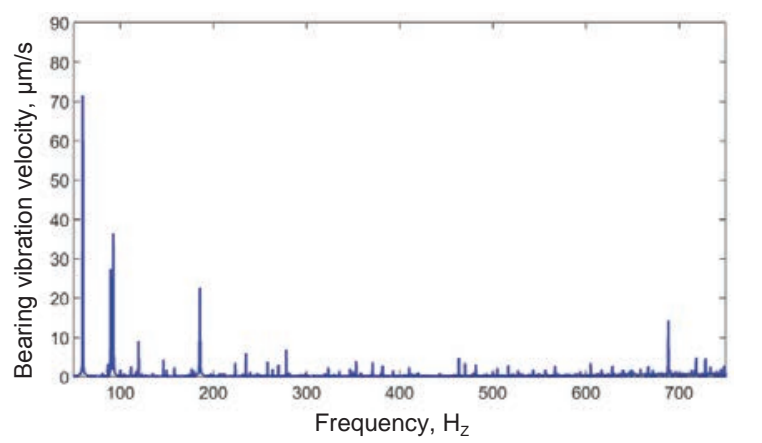

Fig. 3. An example of comparing the vibration spectrum of a 6204 rolling bearing in the $50 \div 700 \mathrm{~Hz}$ range obtained from: a) SG4.3 sensor and $b$ ) PSV-500 head at the same time 
sensor measurements and a laser, around $90 \mathrm{~Hz}$ two components next to each other can be seen. The first corresponds to a frequency of $90 \mathrm{~Hz}$, this is the third harmonic of the rotational frequency. The second one can be identified by the frequency of $92.5 \mathrm{~Hz}$, corresponding to the basic frequency of the outer ring. For the frequency $120 \mathrm{~Hz}$ (the fourth harmonic of the rotational frequency coinciding with the frequency of the second harmonic of the ball rotation) also appears the component that has the lowest amplitude of the six selected for comparative calculations. The next peak assumed for analysis is assigned to the frequency calculated on the basis of the formula, $185 \mathrm{~Hz}$, which corresponds to the second harmonic frequency of the outer ring.

A $690 \mathrm{~Hz}$ component also appears in the spectrum. Harmonics between those discussed and those larger than $690 \mathrm{~Hz}$ do not always appear, which makes them difficult to compare.

To compare the results of two measuring devices, a simple regression plot was drawn for each bearing series, approximating the relationship between the average value of the amplitude of the vibration velocity of each bearing in the range of selected frequencies in the $60 \div 690 \mathrm{~Hz}$ range. The least squares method was used for this purpose. An example of a chart with the measuring points of the $T$ and $N$ series bearings and the regression line are in fig. 4.

The slope and function's $y$-intercept of a simple regression for each of the five bearing series is found in Tab. I. In addition, in Tab. I there are coefficients of determination and Pearson's and Spearman's correlation coefficients. Pearson's correlation coefficient is a measure of the linear relationship between variables. He treats all other relationships as disturbed linear relationships. Rank (Spearman's) correlation shows any monotonic (also non-linear) relationship. The coefficient of determination shows what percentage of measurements with an electrodynamic sensor

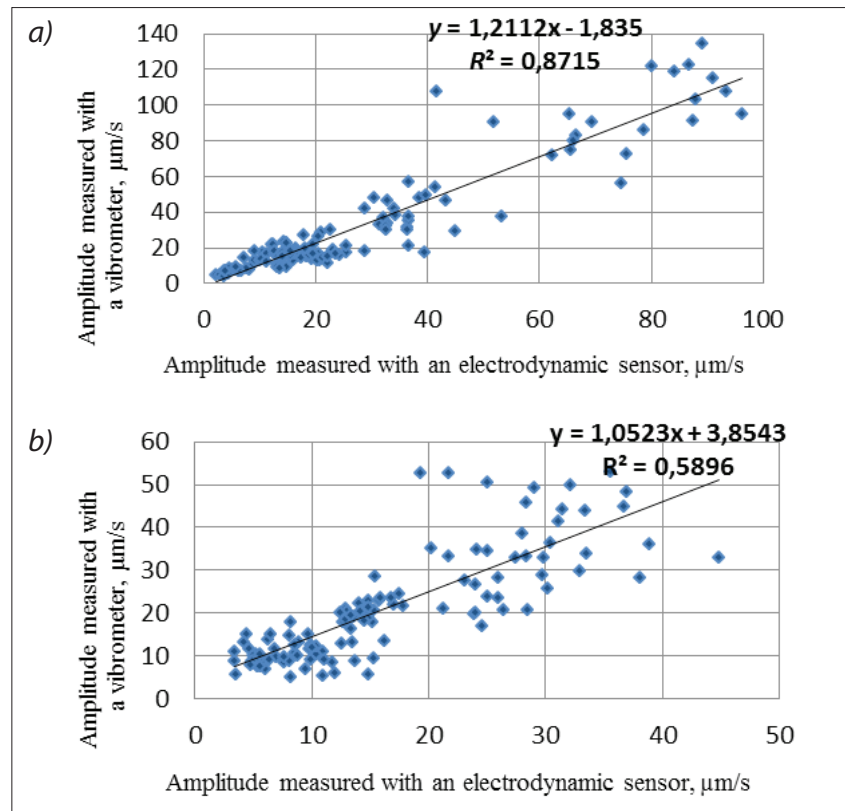

Fig. 4. Relationship between the results of the measurement of the amplitude of vibration velocity of rolling bearings of the 6204 type for SG4.3 electrodynamic sensor and the PSV-500 vibrometer: a) $T$ series and $b$ ) $N$ series
TABLE I. The results of the comparison of the amplitude measurements of the vibration velocity harmonics of rolling bearings by the SG4.3 electrodynamic sensor and the PSV-500 vibrometer

\begin{tabular}{|c|c|c|c|c|c|}
\hline $\begin{array}{c}\text { Bearing } \\
\text { manu- } \\
\text { facturer }\end{array}$ & $\begin{array}{c}\text { Function's } \\
\text { slope }\end{array}$ & $\begin{array}{c}\text { Function's } \\
y \text {-intercept }\end{array}$ & $\begin{array}{c}\text { Pearson's } \\
\text { correlation } \\
\text { coefficient }\end{array}$ & $\begin{array}{c}\text { Determi- } \\
\text { nation } \\
\text { coefficient }\end{array}$ & $\begin{array}{c}\text { Spear- } \\
\text { man's } \\
\text { correlation } \\
\text { coefficient }\end{array}$ \\
\hline$F$ & 1.06 & 3.86 & 0.8 & 0.64 & 0.82 \\
\hline$N$ & 1.05 & 3.85 & 0.77 & 0.59 & 0.85 \\
\hline$T$ & 1.21 & 1.84 & 0.93 & 0.87 & 0.88 \\
\hline$R$ & 1.45 & -5.46 & 0.94 & 0.88 & 0.75 \\
\hline$S$ & 1.25 & 1.59 & 0.81 & 0.66 & 0.84 \\
\hline
\end{tabular}

we explained by the variability of measurements with a laser vibrometer.

\section{Comparison of the vibration signal effective value}

The data obtained from the electrodynamic sensor and the laser vibrometer were also compared on the basis of effective value parameter in three frequency ranges: low: $50 \div 300 \mathrm{~Hz}$, medium: $300 \div 1800 \mathrm{~Hz}$, and high: $1800 \div 10000 \mathrm{~Hz}$. The RMS tested in these bands is typical for the control of newly manufactured rolling bearings. These bands are of course closely related with the rotational speed applied [12-14]. Each of the three bands has different supposed defects. For example, a high RMS value in the low band may indicate, for example, a difference in the diameter of the balls or deviations of the roundness of the rings, in the medium band about ball damage or raceway wave errors, in the high band with too high roughness of the ball or raceway surface, or contamination [15]. Increasing the effective value during bearing operation indicates an increase in the amount of damage. Using RMS as an estimate of the level of bearing vibration is simple, fast and cheap. Bearing manufacturers set RMS limits for each frequency range. If the tested bearing is under the boundary then it is considered to be operating correctly.

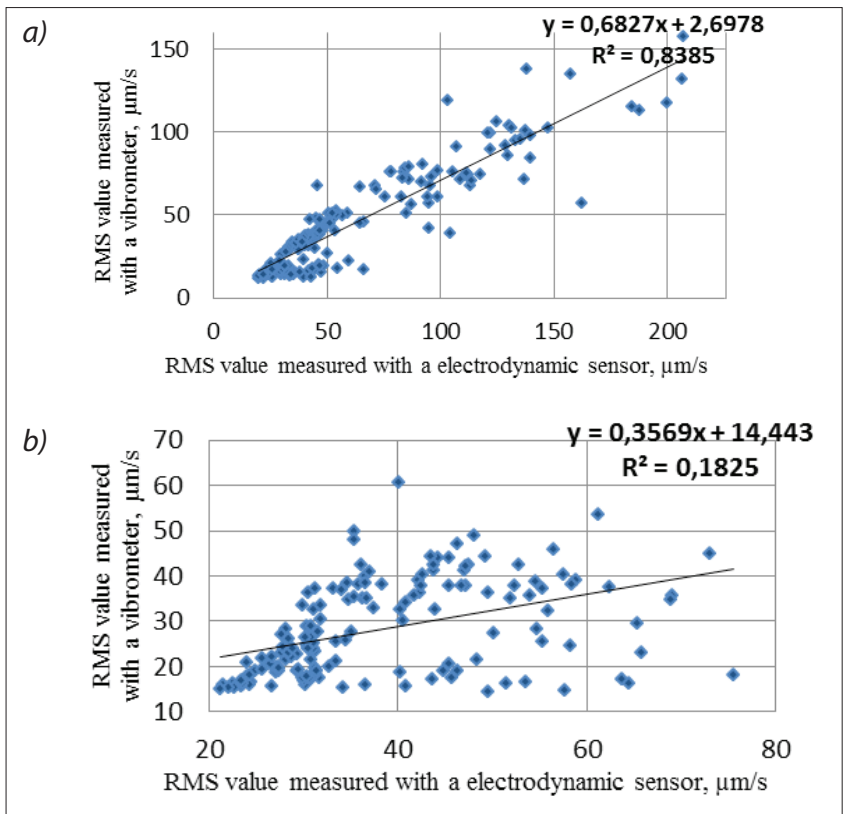

Fig. 5. Relationship between the results of measuring the effective value of the vibration velocity of rolling bearings type 6204 by SG4.3 electrodynamic sensor and a PSV-500 vibrometer: a) $S$ series and b) $R$ series 
As in the case of comparing the amplitudes for each bearing series, a simple regression line was drawn, approximating the relationship between the mean value of the effective value of the vibration velocity of each bearing for the three bands together. The least squares method was used for this purpose. An example of a chart with the measuring points of the $S$ and $R$ series bearings and a regression line are shown in fig. 5. Parameters of linear function for each of the five bearing series are given in Tab. II. In addition, Tab. II contains determination coefficients and Pearson's and Spearman's correlation coefficients.

TABLE II. Results of comparison of the effective value of vibration velocity of rolling bearings by SG4.3 electrodynamic sensor and a PSV-500 vibrometer

\begin{tabular}{|c|c|c|c|c|c|}
\hline $\begin{array}{c}\text { Bearing } \\
\text { manu- } \\
\text { facturer }\end{array}$ & Function's & $\begin{array}{c}\text { Function's } \\
\text { slope }\end{array}$ & $\begin{array}{c}\text { Pearson's } \\
\text { correlation } \\
\text { coefficient }\end{array}$ & $\begin{array}{c}\text { Determi- } \\
\text { nation } \\
\text { coefficient }\end{array}$ & $\begin{array}{c}\text { Spear- } \\
\text { man's } \\
\text { correlation } \\
\text { coefficient }\end{array}$ \\
\hline$F$ & 0.72 & -1.95 & 0.71 & 0.66 & 0.71 \\
\hline$N$ & 0,77 & -2.16 & 0.90 & 0.81 & 0.86 \\
\hline$T$ & 0,63 & 3.10 & 0.77 & 0.59 & 0.74 \\
\hline$R$ & 0.36 & 14.44 & 0.43 & 0.18 & 0.52 \\
\hline$S$ & 0.68 & 2.70 & 0.92 & 0.84 & 0.90 \\
\hline
\end{tabular}

\section{Conclusions}

Measurements of each bearing series with two devices were carried out at the same time, in the same way, with the same measurement conditions and without changing operators. Despite this, different scales of discrepancy were obtained with the standard sensor and non-contact vibrometer. The obtained simple regression coefficients show that the degree of consistency of the results depends on the manufacturer, and thus it is possible that the type and condition of the surface on which the laser beam falls. Both the analysis of the magnitude of the spectrum amplitudes with a specified frequency and the effective value in three frequency bands allows to notice the similarity between the regression models for bearings in the $F$ and $N$ series as well as $T$ and $S$. The simple regression for the $R$ group indicates the least favorable outer surface of the outer ring of these bearings for measurements laser vibrometer.

In general, the results of measurements of selected amplitudes are at least highly correlated as evidenced by Pearson's and Spearman's correlation coefficients. Correlation for groups $T$ and $R$ is almost full. Based on the correlation coefficients for the calculated effective value, we can state a moderate relationship for the $R$ group. A very high correlation can be observed for the $F$ and $T$ bearings, while for the $N$ and $S$ groups an almost full correlation.

As one of the reasons for the differences in amplitude values, we can mention that the laser vibrometer was not associated with the measuring system and could detect not only bearing vibrations, but also the rest of the apparatus. The SG4.3 sensor vibrated with the whole system. The main problem was the collection of data by sensors from two perpendicular directions. The bearing and the entire measuring system may vibrate slightly differently vertically than horizontally.
The presented results show that the use of a laser vibrometer to measure vibration of rolling bearings (e.g. to determine the metrological properties of bearing vibration measurement systems) should be preceded by tests on how the beam interacted with the surface from which the device collects data. Knowing the reasons for the differences and their scale, it will be possible to predict the actual bearing vibrations with good accuracy. The PSV-500 is a scanning vibrometer for testing the vibrations of larger objects than the bearing. A more compact device associated with the STPPD measuring system could be a single point vibrometer with the smallest possible spot diameter.

The direction of further tests should be comparative tests using a compact head with the tested stand with a single-point laser. Surfaces that the laser falls on in terms of structure, condition, geometry or absorbance of the external surfaces of manufactured rolling bearings should also be examined, and thus an attempt to produce such a surface that will be most suitable for the Doppler beam of the laser vibrometer.

\section{REFERENCES}

[1] Palmetshofer W. "Contactless vibration measurement for condition monitoring". Evolution. 4 (2013): 27-30.

[2] Castellini P., Martarelli M., Tomasini E.P. "Laser Doppler Vibrometry: Development of advanced solutions answering to technology's needs". Mechanical Systems and Signal Processing. 20, 6 (2006): 1265-1285.

[3] Valliapan R., Lieu D.K. "Defect characterization of roller bearing surfaces with laser Doppler vibrometry". Precision Engineering. 14, 1 (1992): 35-42.

[4] Georgeson J.D., Lieu D.K. "Inspection of roller bearing surfaces with laser Doppler vibrometry". Journal of Engineering for Industry. 114, 1 (1992): 123-125.

[5] Vass J., Cristalli C., Torcianti B., Sovka P., Smid R. "Reducing speckle noise in vibration signals measured with laser Doppler vibromety". SPIE Newsroom. 10. 1117/2.1200609. 039 (2006).

[6] Dzwonkowski A., Swędrowski L. „Motor bearing diagnostics performed by means of laser vibrometer". Diagnostics for Electric Machines Power Electronics \& Drives (SDEMPED). 2011 IEEE International Symposium. (2011): 482-486.

[7] Nassif H.H., Gindy M., Davis J. "Comparison of laser Doppler vibrometer with contact sensors for monitoring bridge deflection and vibration". NDT \& E International. 38, 3 (2005): 213-218.

[8] Rodriguez R.M., Cristalli C., Paone N. "Comparative study between laser vibrometer and accelerometer measurements for mechanical fault detection of electric motors". Proc. SPIE 4827. Fifth International Conference on Vibration Measurements by Laser Techniques: Advances and Applications (2002).

[9] Aye S.A. "Bearing damage characterization using SVAN 958 and laser in the time domain". $10^{\text {th }}$ Intl Conference on Vibration Measurements by Laser and Noncontact Techniques (2012).

[10] Adamczak S., Stępień K., Wrzochal M. "Comparative study of measurement systems used to evaluate vibrations of rolling bearings". Procedia Engineering. 192 (2017): 971-975.

[11] Ewert P., Kowalski C. „Ocena skuteczności wykrywania uszkodzeń elementów konstrukcyjnych łożysk tocznych w silnikach indukcyjnych". Prace Naukowe Instytutu Maszyn Napędów i Pomiarów Elektrycznych Politechniki Wrocławskiej. 64 (2010): 293-294

[12] Adamczak S., Zmarzły P. "Influence of raceway waviness on the level of vibration in rolling-element bearings". Bulletin of the Polish Academy of Sciences Technical Sciences. 65, 4 (2017) 541-551.

[13] Norma ISO 15242-1:2015: Rolling bearings - Measuring methods for vibration - Part 1: Fundamentals (2015).

[14] Lacey S.J. "An overview of bearing vibration analysis". Maintenance \& Asset Management. 23, 6 (2008): 32-42.

[15] Adamczak S., Zmarzły P., Stępień K. "Identification and analysis of optimal method parameters of the V-block waviness measurement". Bulletin of the Polish Academy of Sciences Technical Sciences. 64, 2 (2016): 325-332. 